\title{
Organic Functionalization and Optical Properties of Carbon Onions
}

\author{
Vasilios Georgakilas, ${ }^{1}$ Dirk M. Guldi, ${ }^{2 *}$ Raffaella Signorini, ${ }^{3}$ Renato \\ Bozio, $^{3 *}$ and Maurizio Prato ${ }^{1 *}$
}

\begin{abstract}
${ }^{1}$ Dipartimento di Scienze Farmaceutiche, Università di Trieste, Piazzale Europa, 1, 34127
Trieste, Italy. ${ }^{2}$ Radiation Laboratory, University of Notre Dame, Notre Dame, IN 46556, USA. ${ }^{3}$ Dipartimento di Chimica Fisica, Università di Padova, Italy.
\end{abstract}

\section{Supporting Information}




\section{Experimental Section}

General procedure. Arc discharge carbon material (50 mg, BU-202, as received from Bucky-USA, http://www.flash.net/ buckyusa/) was suspended in $50 \mathrm{ml}$ of toluene. NFunctionalized amino acid $1(100 \mathrm{mg})$ and paraformaldeyde $(200 \mathrm{mg})$ were added and the mixture was stirred at $100^{\circ} \mathrm{C}$ for 4 days. After cooling to room temperature the toluene phase was removed by filtration and the residue was washed with toluene and then dissolved in chloroform (sol_1, $150 \mathrm{ml}$ ). The toluene phase contains any functionalized fullerenes, and other very soluble carbon impurities.

After one week, the chloroform phase (sol_1) shows a precipitate $\left(\mathrm{P}_{-} 1\right)$, which was removed by centrifugation living a green-black transparent solution (sol_2). The precipitate $\left(\mathrm{P}_{-} 1\right)$ was analysed by TEM showing mostly amorphous carbon (Figure S1S2).

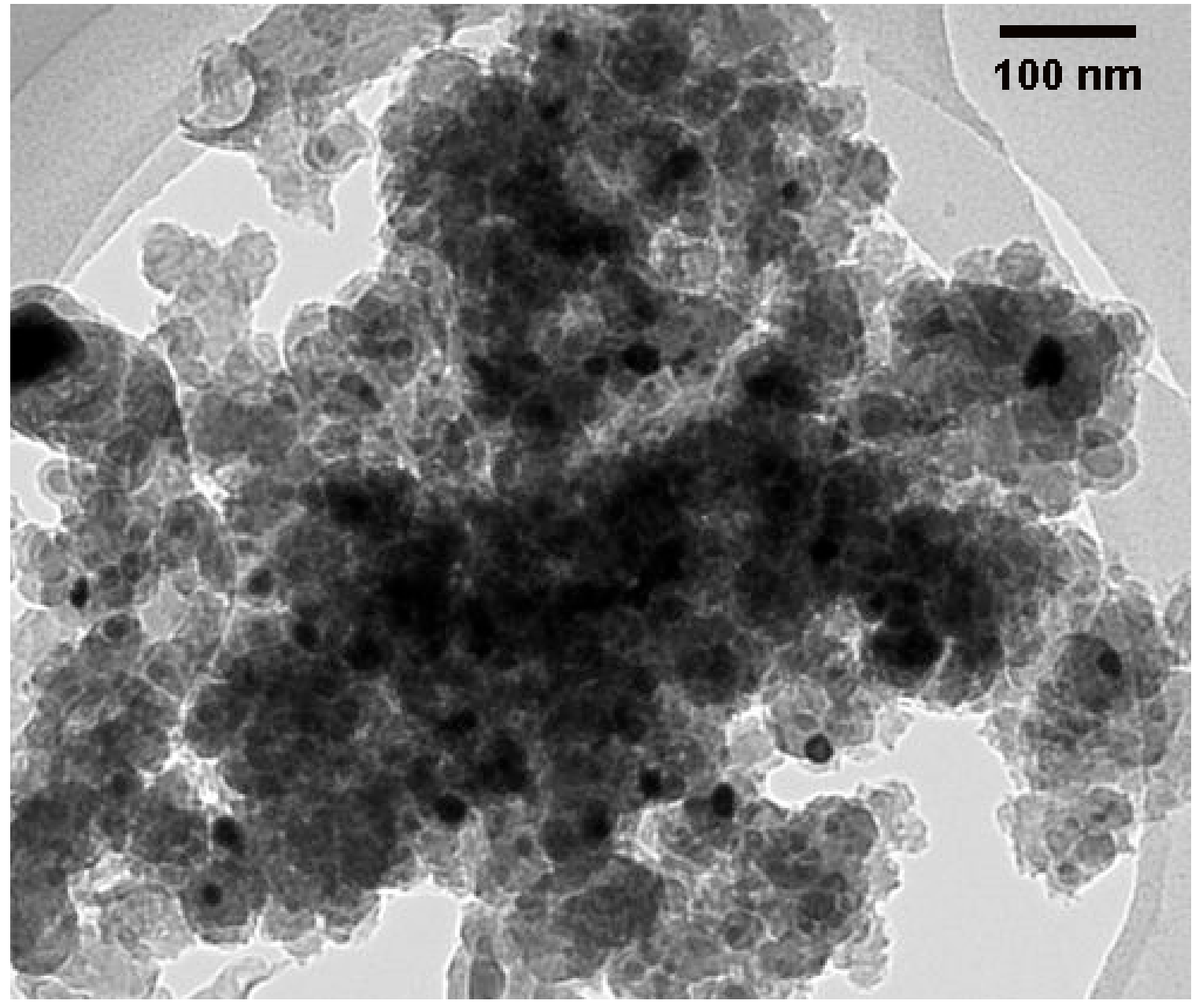




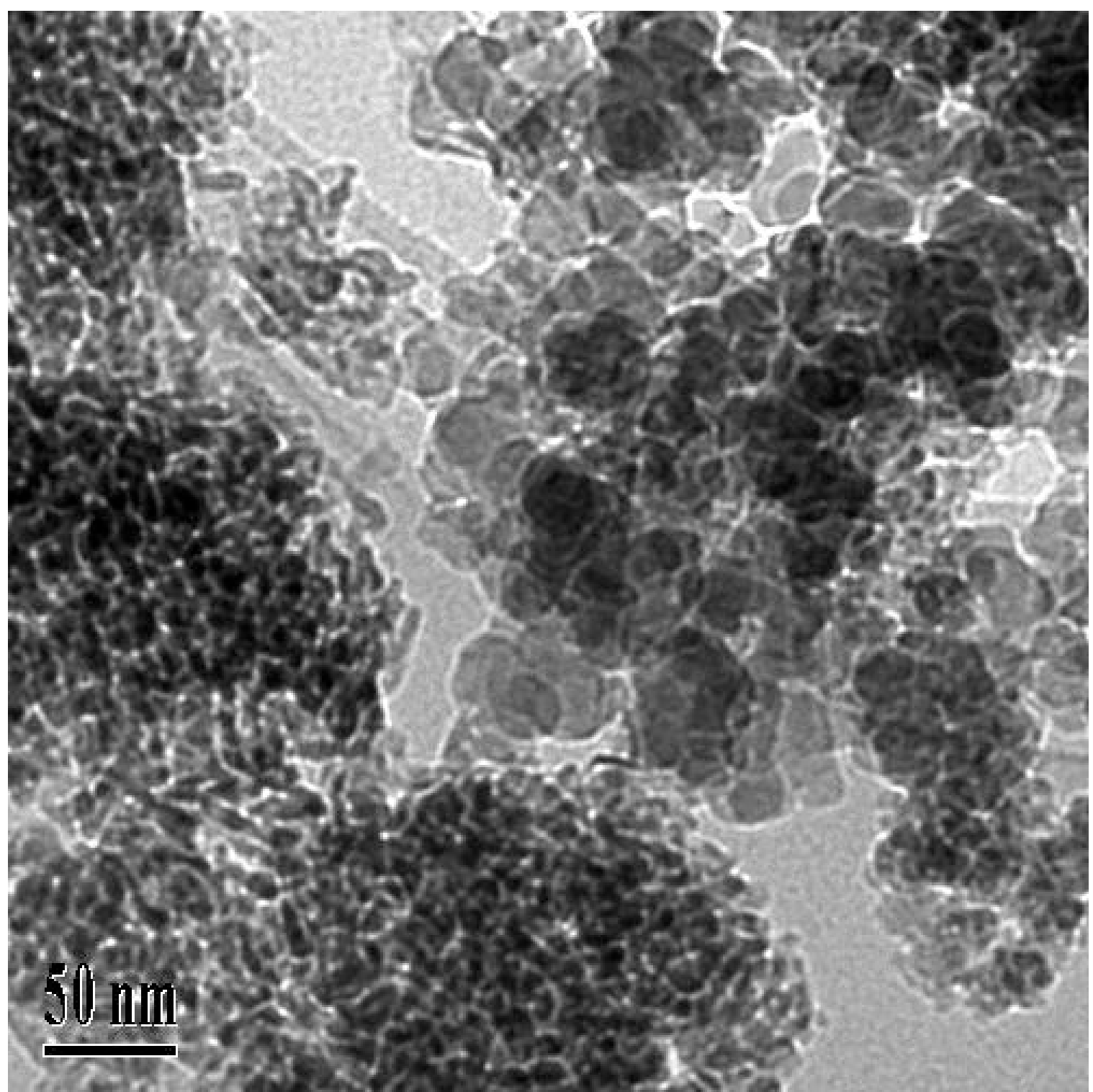

Figures 1 and 2. TEM photos of amorphous carbon as a byproduct, which precipitates from the chloroform solution.

Evaporation of the solvent from the transparent solution (sol_2) led to the isolation of 7 mg of black solid (P_2). The latter ( $\left.\mathrm{P} \_2\right)_{2}$ was analysed by TEM, consisting mostly of onion structures (c.f. Figure 1 in main text). 


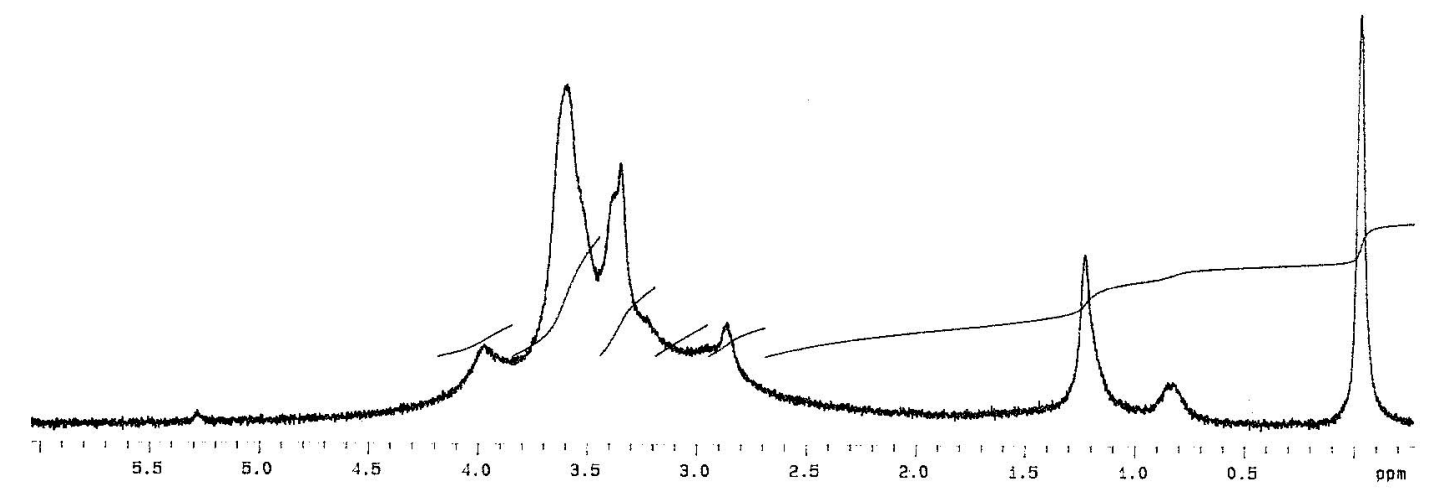

Fig. S3. ${ }^{1} \mathrm{H}-\mathrm{NMR}$ of the functionalised onions $\left(\mathrm{CDCl}_{3}\right)$.

MALDI mass spectrometry and elemental analysis. Maldi mass spectrometry (see below) shows a broad peak with masses centered at $2713 \mathrm{~m} / \mathrm{z}$. Since the functionalized onions possess a very high molecular weights, we may not see the molecular ions, but we clearly observe relevant peaks centered at $178\left(\mathrm{CH}_{3} \mathrm{OCH}_{2} \mathrm{CH}_{2} \mathrm{OCH}_{2} \mathrm{CH}_{2} \mathrm{OCH}_{2} \mathrm{CH}_{2} \mathrm{NH}+\right)$ $194 \mathrm{~m} / \mathrm{z}$ (previous at $178+\mathrm{O}$ ), indicative of the presence of the oligoethylene chain. Elemental analysis gives the following results: $\mathrm{C}, 54.32 \% ; \mathrm{H}, 5.54 \%$; N, 1.75\%, ash 15.2 $\%$, clearly showing the presence of nitrogen in the compound. 


\section{- Finnigan} mat
LASERMAT: Matrix Assisted

Laser Desorption Mass Spectrometry

Spectrum printed at 08:18 Wed Sep 032003

Sample:

Fullerene Onions 9NA

Operator:

Account No:

Data File:

C:IDATAIDAGInd.002

Saved on:

08:18 Wed Sep 032003

$\begin{array}{llccc}\text { No of shots: } & 20 & \text { Laser Aim: } 3 & \text { Laser Power: } 33 \\ \text { Polarity: } & \text { Positive } & \text { Acc. Voltage: } 20004 & \text { Gain: } 31 \mathrm{mV} \\ \text { Calibration: } & \text { External } & \text { Mass 1: } 0.0 & \text { Mass 2: } 1348.7 \\ \text { Pk. Detect: } & \text { DG.CAL } & \text { A: }-0.034 & \text { BN: } 0.524510 \\ \text { Autosamp pos: } & 1 & & & \end{array}$

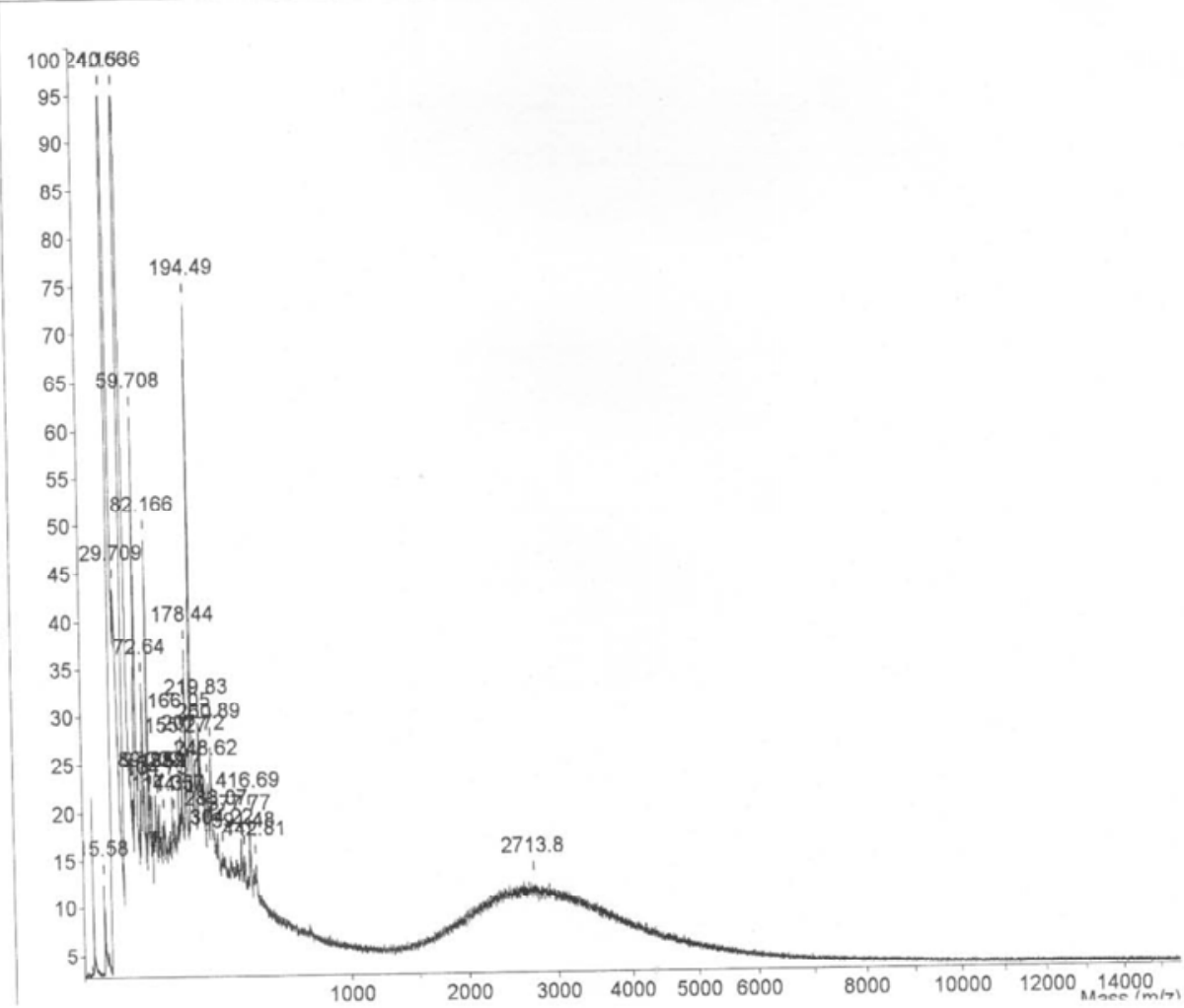


TEM analysis. The sample was dispersed in acetone and one drop of the mixture was deposited onto a TEM grid (copper grid $3.0 \mathrm{~mm} 200$ mesh, coated with formvar film) together with a drop of diluted uranyl acetate (2\% water solution). TEM analysis was carried out with a Philips TEM 208 electron microscope operated at $100 \mathrm{kV}$.

Optical measurements. Nanosecond laser studies were performed with laser pulses from a Molectron UV-400 nitrogen laser system (337.1 nm, $8 \mathrm{~ns}$ pulse width, $1 \mathrm{~mJ}$ / pulse) or from a Lambda Physik COMPex Excimer laser (308 nm, 20 ns width, 5 mJ / pulse) or from a Quanta-Ray CDR Nd:YAG system (532 nm, 6 ns pulse width, $5 \mathrm{~mJ} /$ pulse). Fluorescence lifetimes were measured with a Laser Strobe Fluorescence Lifetime Spectrometer (Photon Technology International) with $337 \mathrm{~nm}$ laser pulses from a nitrogen laser fiber-coupled to a lens-based T-formal sample compartment equipped with a stroboscopic detector. Emission spectra were recorded with a SLM 8100 Spectrofluorometer. The experiments were performed at room temperature.

Nonlinear optical measurements on 2 in solution were performed using $0.5 \mathrm{mg}$ in 5 $\mathrm{ml}$ of $\mathrm{CHCl}_{3}$. The linear absorption spectra were taken in chloroform using a Cary 5 spectrophotometer, in a $10 \mathrm{~mm}$ quartz cell, in the range from $250 \mathrm{~nm}$ to $1100 \mathrm{~nm}$ or in methylene chloride. Optical limiting (OL) measurements were performed using a Qswitched Nd-YAG laser emitting $12 \mathrm{~ns}$ pulses at either $532 \mathrm{~nm}$ or $1064 \mathrm{~nm}$, with $2 \mathrm{~Hz}$ repetition rate. The laser beam, of diameter $6 \mathrm{~mm}$ at $532 \mathrm{~nm}$ and $7 \mathrm{~mm}$ at $1064 \mathrm{~nm}$, was focused onto the sample using a $200 \mathrm{~mm}$ lens and collimated, after the sample, with a 170 $\mathrm{mm}$ lens. The incident and transmitted laser pulse energies were measured by using photodiodes calibrated against the signal from a surface absorbing calorimeter and recorded with a digital oscilloscope (60 MHz TDS 210 Tektronix). The energy of the input beam was varied between $5 \cdot 10^{-3} \mathrm{~mJ}$ to $1.5 \mathrm{~mJ}$, at $532 \mathrm{~nm}$, and $5 \mathrm{~mJ}$, at $1064 \mathrm{~nm}$, with a set of absorbing filters. In the IR region a cut-off filter, the RG830, has been used to eliminate a residual $532 \mathrm{~nm}$ component from the laser. 

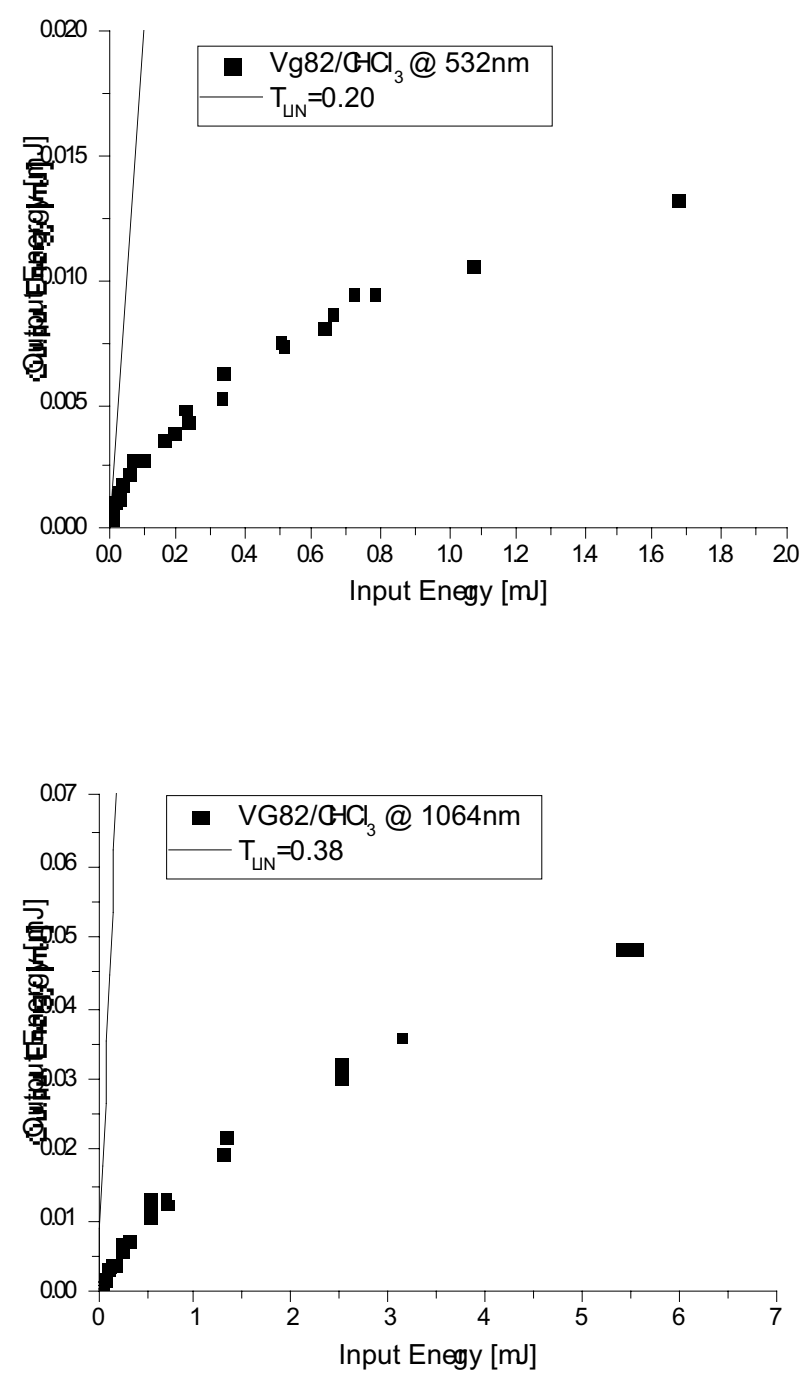

Figure S4. Optical limiting plots at (upper) $532 \mathrm{~nm}$ and (lower) $1064 \mathrm{~nm}$. 